\title{
EL TALLO CALCINADO DE LA MORGUE. \\ LAS MORGUES DE LA GLOBALIZACIÓN EN LAS ESCRITURAS DE FERNANDO VALLEJO, ROBERTO BOLAÑO Y JACQUELINE GOLDBERG
}

\section{THE BURNED STEM OF THE MORGUE. THE GLOBALISATION'S MORGUES IN THE FERNANDO VALLEJO, ROBERTO BOLAÑO AND JACQUELINE GOLDBERG WRITINGS}

\author{
Daniuska González González \\ Centro de Estudios Avanzados (CEA) \\ Universidad de Playa Ancha \\ daniuska.gonzalez@upla.cl
}

\begin{abstract}
Resumen:
Este artículo de investigación pretende un acercamiento a la representación del espacio de la morgue en tres autores latinoamericanos: Fernando Vallejo (Medellín, Colombia, 1942), Roberto Bolaño (Santiago de Chile, 1953-Blanes, Barcelona, España, 2003) y Jacqueline Goldberg (Maracaibo, Venezuela, 1966), buscando una mirada que rompa con la apropiación tradicional, que lo analiza desde el lugar común de la repulsión por la muerte. En este sentido, se leerá la morgue a partir de su inserción en las dinámicas de la globalización, las cuales la han transformado en un sitio residual, botadero de cuerpos sin identificación y de objetos como últimos restos de la violencia neoliberal. Para esta aproximación, se contará con el soporte teórico de autores como Zygmunt Bauman, Jean-Luc Nancy, Jean Baudrillard y José Ovejero.
\end{abstract}

Palabras clave: morgue, globalización, cuerpo, violencia, narrativa latinoamericana contemporánea.

\begin{abstract}
:
This research article tries an approach to the representation of the morgue space in three Latin American authors: Fernando Vallejo (Medellin, Colombia, 1942), Roberto Bolaño (Santiago de Chile, 1953-Blanes, Barcelona, Spain, 2003) and Jacqueline Goldberg (Maracaibo, Venezuela, 1966), looking for a glance that breaks with the traditional assumption, that analyzes it from the common place of death repugnance. In this sense, the morgue will be read from its insertion in globalisation dynamics, which has transformed it into a residual site, landfill of bodies without identification and objects like the last rest of neoliberal violence. For this approach, it will be counted on the theoretical support of Zygmunt Bauman, Jean-Luc Nancy, Jean Baudrillard and José Ovejero.
\end{abstract}

Keywords: morgue, globalisation, body, violence, contemporary Latin American narrative.

Recibido : 21/6/2016

Aceptado:30/11/2016 
Todo está pulcro y preparado para el corte. Los cuchillos humean. El abdomen marcado.

Bajo paños blancos hay algo que gime.

"Señor profesor, todo está listo."

La primera incisión. Como si el pan se rebanara.

"¡Pinzas!" Algo púrpura brota.

Más profundo. Los músculos: húmedos, brillantes, frescos. ¿Hay un ramo de rosas sobre la mesa?

Silencio, pesado, húmedo. En el vacío tintinea una tijera en el suelo.

$Y$ la enfermera angelical ofrece algodones esterilizados.

(...)

Vientre cerrado, Piel cosida. "iEsparadrapos, acá! Buenos días señores." La sala se vacía.

"Apéndice", Gottfried Benn

\section{Introducción}

El libro Cadáveres Exquisitos (Coroner, título original, publicado en 1983 y traducido por primera vez al español en 2011) resulta una obra singular. Contiene una zona de oscuridad que revela su autor, el médico forense norteamericano Thomas Noguchi: la autopsia del cuerpo célebre. Frente a la provocadora y tradicional imagen del vestido de Marilyn Monroe levantado por el aire de la rejilla del subterráneo neoyorkino, el lector percibe que con las fotografías de la Oficina Forense de Los Ángeles y la rigurosa descripción de la autopsia realizada por Noguchi ${ }^{1}$ puede evocar otro cuerpo, el de la deflagración que anula la belleza, y el de un espacio que sólo se nombra a través de lo inerte y lo descomposición: el de la morgue ${ }^{2}$.

Este libro originó reflexiones personales para pensar la morgue a partir del contraste entre estos cadáveres exquisitos de Noguchi y los miles de cuerpos apilados en las morgues latinoamericanas, a la espera del forense, muchos sin identificación, otros - ¿será osado decir que la mayoría?- trasvasados por historias de violencia ${ }^{3}$, una

\footnotetext{
${ }^{1}$ También los cadáveres de los actores Natalie Wood, Sharon Tate, William Holden y John Belushi, de la cantante Janis Joplin y del senador Robert F. Kennedy aparecen reconstruidos a partir de los detalles que la muerte les configuró: "Un [...] hematoma difuso [...] cubría un lado del brazo derecho de Natalie Wood" (Noguchi 29) o "en las venas de sus brazos [los de Janis Joplin] se hallaron múltiples marcas de pinchazos" (149). Nada glamoroso queda de estos personajes, sólo la rigidez y una fragilidad que los humaniza, lejos ya del divismo que elaboraron para la sociedad y para sí mismos.

${ }^{2}$ No fue hasta el siglo XV parisino que el término morgue cobró significado en tanto lugar para el almacenamiento, la preparación y la identificación de los cadáveres, como se conoce en la actualidad.

${ }^{3}$ Los textos que se trabajarán apuntan a la representación de un tipo particular de violencia, la urbana, aquella propia de las metrópolis, y que resulta "innegable, ubicua y creciente" (Monsiváis "Ciudadanía y
} 
violencia cada vez más superficial. Como los propios países que las contienen, estas salas de autopsias populares, laicizadas, son tercermundistas.

Para Jacques Derrida "Cada muerte supone el fin de un mundo [...] el fin de un mundo único, un mundo que no podrá jamás reaparecer o ser resucitado de nuevo". La morgue se ha convertido en depósito de la muerte globalizada, por permeable y banal, y paradójicamente en el no-lugar en tanto encierro de la no-vida ${ }^{4}$. Sus relatos son atravesados por la descomposición corporal, el bisturí o las sábanas que cubren (o en su defecto revelan) los fragmentos de cuerpos inmóviles y donde lo macabro se enquista por doquier. La morgue semeja un submundo al cual se accede por una situación límite como la de la muerte, de ella brota "una conciencia dolorosa del fracaso al que está condenada cada vida de hombre" (Ariès 115), último eslabón entre un cuerpo que aún puede mirarse y la fugacidad de esta visión cuando comienza a descomponerse. Morgue que petrifica, Morgue-Medusa.

En Miedo líquido Zygmunt Bauman da cuenta de la muerte como uno de los temores centrales de la modernidad globalizada, que no por temor carece de un añadido de banalidad. En claro diálogo con Aldous Huxley y Un mundo feliz expone que "Nuestros cuentos morales tratan de vacunarnos contra el miedo a la muerte banalizando la visión misma de la agonía. [...] [para que] antes de que la muerte llegue [...] nos hayamos habituado a su banalidad" (45). Dentro de una dinámica sostenida por el individualismo como telos predeterminado para la consumación de la vida social, la muerte se ha vuelto otro de los tantos discursos arreglados por conveniencia, superficialidad y egoísmo bajo la parálisis de la fascinación (sospechosamente creativa al generar infinidad de representaciones culturales) por lo "realmente incognoscible" (Bauman 46).

La muerte deviene otra de las instancias discursivas trituradas por la globalización que le impone un significado efímero y la desconnota del carácter mitológico $^{5}$ y sagrado del tradicionalismo religioso ${ }^{6}$. "La banalización trae la

violencia urbana: pesadillas al aire libre" 231), soldada sobre todo a las sociedades latinoamericanas por "el fenómeno de la desigualdad" (231).

${ }^{4}$ En este artículo no se trabajará la ciudad y sus imaginarios, sin embargo, se realizó una revisión del libro La muralla enterrada (2001) de Carlos Franz buscando alguna iluminación sobre cómo ver el cambio en la elaboración cultural de la morgue dentro de la ciudad contemporánea.

5 Entendiendo que para Barthes la muerte se enuncia como una de "las grandes formas neutras de los lugares comunes cósmicos": "Los ritos, los hechos culturales nunca se vinculan con un orden histórico particular, con una situación económica o social explícita, sino solamente con las grandes formas neutras de los lugares comunes cósmicos (estaciones, tormentas, muerte, etc.)” (Barthes Mitologías 92). 
experiencia única de la muerte [...] al terreno de la rutina diaria de los mortales, transformando la vida de éstos en un ensayo perpetuo de la muerte" (60), subraya Bauman. Queda entonces la superficialidad que termina por invadirla, tanto dentro de su proceso como de lo que ha sido su locación específica, la morgue, objetivo del presente artículo.

Recordando la idea de Jankélévitch acerca de que las muertes difieren en revelación, ilustración e instrucción, qué espacio más apropiado que el de la morgue para leer la muerte con igual gradación de potencia reveladora, ilustrativa e instructiva y cómo a partir de ella la literatura se vuelve receptáculo. Hay un saber asumido acerca de que produce horror, también desasosiego, cuando se recorre (o se imagina) una sala de autopsia con sus mesas de disección, su temperatura gélida y los cuerpos inertes. Allí se instalan el vacío y la angustia, esta última tiene su raíz en la somatización de la naturaleza mortal para Julia Kristeva. El lugar alcanza la propiedad de lo que enuncia.

En este tiempo líquido de la contemporaneidad, la violencia de las calles latinoamericanas reactualiza la morgue, desacralizándola de privilegios o de "los hilos de simpatía e intimidad con los que se tejen las relaciones entre 'tú y yo'" (Bauman 62): el rostro casi siempre plácido del fallecido por su avanzada edad, característico del depósito de cadáveres decimonónico, explota frente a la cara descompuesta, con ojos que no se cierran, del sicario abatido en un enfrentamiento. Las "fotos posando con el cadáver [de Pablo Escobar] como un trofeo" (Salazar La parábola de Pablo. Auge y caída de un gran capo del narcotráfico 346) se anticipan al organismo destrozado que entró al Anfiteatro de Medellín para practicarle la autopsia. O la fotografía en el periódico venezolano El Nacional (13 de agosto de 2010) donde la morgue caraqueña de Bello Monte se transformó en un gran receptáculo de cadáveres apilados, retorcidos, sin individualidad, en "una escena primitiva [...], donde [se] alcanzaría las fantasmagorías inhumanas de todas las culturas anteriores a la nuestra" (Baudrillard El crimen perfecto 112), en la dirección de erigirse el artefacto fotográfico en la suma de las pesadillas más recurrentes de nuestra psiquis cultural con respecto a la muerte.

La morgue establece un diálogo con la globalización, sus espacios de interacción, entre ellos el de la ciudad, y con las subjetividades (el sicario que recorre la narrativa colombiana o el sujeto que muere y a quien su pequeña hija sobrevive en la soledad de un apartamento citadino resultan algunas de éstas, como se analizará más

\footnotetext{
${ }^{6}$ En Mitologías de Roland Barthes y en Documentos, Las lágrimas de Eros, El erotismo y La oscuridad no miente de Georges Bataille.
} 
adelante) que se elaboran en un proceso parecido al de la rumia pues es constante, tedioso y recurrente. Traspasando la idea del libro La muralla enterrada de Carlos Lanz, la morgue sería un imbunche, "una sede del horror, un anus mundi" (199).

En este sentido, los cadáveres comunes encima de mesas sucias o en el piso cruzan la escritura de autores de la literatura latinoamericana contemporánea como Fernando Vallejo (Medellín, Colombia, 1942), Roberto Bolaño (Santiago de Chile, 1953-Blanes, Barcelona, España, 2003) y Jacqueline Goldberg (Maracaibo, Venezuela, 1966). En éstos la morgue se vuelve amontonamiento y vulgaridad, sin cabida para una posible belleza deslumbrante (Noguchi) como la de Monroe sobre la mesa de autopsia número uno; tampoco para informes con la precisión que merecen los deudos que aguardan. Nada exquisito puede brotar de este lugar. Tal como Eduardo Sánchez Rugeles describe a la morgue de Bello Monte en su novela Jezabel, "Todo era feo, muy feo. Yo nunca había visto un lugar como la morgue [...]. [es como] saber cómo le huele el culo al diablo" (132).

Si el horror instaura un punto de reacción intensa entre el espectador y el objeto que la produce, "el horror remite necesariamente a una instancia material, sensible" (Pérez Morales 78), puede enfocarse la morgue desde esta perspectiva. Sólo la racionalidad se impone cuando se observa este objeto que origina la condición hórrida: no se trata de una sensación sino de un proceso lúcido por el cual transcurre el encuentro entre el individuo y la cosa. En la representación literaria de la morgue contemporánea, el horror se hace ordinario y los registros a su alrededor juegan a armarse/desarmarse con una puesta en escena banal de la muerte.

\section{La autopsia teatral de la violencia. La virgen de los sicarios de Fernando Vallejo}

Las breves pero intensas páginas sobre la morgue en La virgen de los sicarios ${ }^{7}$ hilvanan un entramado desolador. El primer rastro para llegar hasta ésta resulta paradójico: se asocia con la palabra "Anfiteatro" porque así la "llaman aquí [en Medellín]" (Vallejo La virgen de los sicarios 167). De entrada este Anfiteatro no está "levantado" al azar; para el año de la edición de la novela, 1994, se ubicaba en la ciudad

\footnotetext{
${ }^{7}$ A María Auxiliadora se la llamó "la Virgen de los sicarios y [...] su fama se extendiera por doquier, especialmente entre los malandros que, de muchos rincones, acudieron a ella presurosos y piadosos a pedirle que sus empresas, siempre contrarias al Código Penal, tuvieran éxito" (Salazar La parábola de Pablo. Auge y caída de un gran capo del narcotráfico 127).
} 
más violenta de Colombia, apenas había transcurrido un año de la muerte de Pablo Escobar Gaviria, el jefe del cártel de Medellín. Ciudad-escenario de enfrentamientos entre narcotraficantes; un reguero de cadáveres y edificios dinamitados la convirtieron en locus del horror, con otra dimensión a la que Bolaño le impregnará a Ciudad Juárez, como se abordará, pero ambos lugares ensombrecidos por la barbarie y la impunidad. Medellín fue el epicentro de "visibilización de sujetos y de zonas que se tenían por relegadas al olvido" (Salazar La parábola de Pablo. Auge y caída de un gran capo del narcotráfico 170): los jóvenes desempleados de barriadas populares quienes se vendieron al mejor postor, los cárteles, "padres" de una de las subjetividades más dinámicas de la cultura depredadora ${ }^{8}$ : el sicario. "Otra decena de carros detonaron en las siguientes semanas en Medellín y el plan pistola contra agentes secretos de la Policía habría de dejar cerca de sesenta muertos en dos meses" (381), relata el propio hijo del capo, Juan Pablo Escobar Henao.

El "Anfiteatro" como una tabla de representación y disfraz, difícil sinónimo para este sitio de muerte. Sin embargo, los cadáveres sobre las mesas de disección, las neveras donde se alojan, la ritualidad cansina del forense y sus ayudantes cuando realizan la autopsia, ¿no construyen, acaso, un montaje cuya mirada trasciende el espacio interior para acceder a los ojos públicos del reconocimiento familiar o del traslado hacia la fosa común?

Escenario para colocar el duelo sobre éste, el gesto histriónico del dolor y la impotencia, "el llanto de los vivos y el silencio de los muertos" (Vallejo 168). Como en la preparación que antecede una obra, se maquilla el rostro inerte, se recomponen los cuerpos y se agotan los recursos para aplacar la degradación. La morgue teatraliza la muerte, anfiteatro donde tanto las víctimas como los deudos intercambian un lenguaje de marcas y (des)memorias y donde la vida se expone a la intemperie porque cesó en su latencia.

Esta morgue/Anfiteatro vallejiana lleva soldada un carácter científico, deslavado de metáforas: "heridas de la vena cava y paro cardiorespiratorio tras el shock hipovolémico causado por la herida de arma corto punzante" (Vallejo 168). La grandilocuencia de la terminología, cierta rimbombancia para el episodio de la

\footnotetext{
${ }^{8}$ Concepto enunciado por Alonso Salazar en "Hacia una estrategia de la reconstrucción cultural" y que remite al teórico Francisco de Roux, para quien significa que "no valoramos ni las selvas ni las vidas" (173).
} 
violencia, también forman parte del guión teatral, de una caracterización de quienes lo enuncian, como en una escenografía arreglada por la desidia:

sobre los pies de uno de esos cadáveres había otro, pequeñito, orientado en sentido vertical como los brazos de una cruz: el de un bebé recién nacido y recién rajado. Por un instante el hombre invisible pensó que el cadáver de la persona adulta era el de una mujer, la mamá, a la que le habían hecho la cesárea puesto que también tenía el vientre rajado. Pero no, era un hombre, otro más, y le habían puesto encima el cuerpecito del niño porque simplemente no tenían mesa vacía donde acomodarlo. (170).

Como detrás del telón del teatro, hay un ojo que panea sobre la trama, donde la imaginación pesa sobre la realidad: un embarazo que culminó fatalmente, madre e hijo vinculados hasta el último lugar posible, la morgue; y la criatura, dispuesta en forma de cruz, escenifica una imagen que se elaboró desde uno de los referentes más crueles del imaginario cristiano: la crucifixión de Jesús. Estos personajes inermes sólo constituyen "combinaciones de objetos mágicas, insólitas con que soñaban los surrealistas, como por ejemplo un paraguas sobre una mesa de disección" (Vallejo 170). Sobre el cadáver del hombre desconocido este recién nacido espera el reclamo y no existe asomo de benevolencia, nada le será concedido. Está solo, violentado en su pose, como un objeto de utilería, sin piedad que lo cubra.

Este momento transcurre rápidamente y su descripción minimalista permite un acercamiento a la crueldad "porque [ésta] tiende a ser impenetrable, se presenta [...] como superficie que no podemos atravesar, rehúsa el sentido" (Ovejero 70). El narrador pasa veloz sobre la escena, como si pretendiera impactar de golpe al lector, sin sutilezas, rehusando el sentido; y este paso se asemeja a la rapidez de las imágenes que sobresaturan la cotidianidad mediática globalizada.

Para Vallejo la morgue instala el anonimato como su rasgo más profundo. Salvo las etiquetas atadas a un dedo en las cuales se mezclan números y letras, poco se sabe sobre la identidad de estos cuerpos tirados con absoluta dejadez, desechos y amorfidades de la sinrazón, "corazon[es] que [no pueden] volver a sentir el odio" (Vallejo 169).

A diferencia del "cadáver exquisito" estos cuerpos depositados en el "Anfiteatro" se marginan de cualquier intención de embellecimiento: sobre ellos la muerte se ha endurecido sin retoque. De ahí los ojos abiertos del sicario Wílmar que "no pude cerrar por más que quise" (Vallejo 171), los ojos verdes y sin contenido, "mirando sin mirar, en la eternidad" (171); los ojos como remanentes de vaciedad dentro de la no-vida de las 
cavas. Ojos que ya estaban vacíos antes de su muerte; ojos de la violencia, ojos fugaces; los ojos del sicario, imposibles de "adivinarle[s] el alma" (22). La morgue de Medellín deviene punto de sutura, el destino final de la violencia que se enquista en la sociedad como fuerza motriz (casi siempre anónima) y recibe al "sujeto-fuerza que infringe daño" (Reguillo 197), en este caso el sicario.

Pero en la novela coexisten otros dos apartados. El primero incrusta la muerte como rasero, con las pieles de los cadáveres idénticas al colocarles un "color translúcido" (Vallejo 172), sin separación entre las víctimas y los victimarios. La diferencia ha desaparecido con esta transparencia común que deja los cuerpos "como santos coloniales de madera policromada, [...] con colorcitos discretos, lívidos, de opalino a alabastrino" (172). Nada evoca la singularidad durante la vida, ahora los sujetos se indistinguen en la morgue, compactados como una masa sin texturas individuales. Es en este momento, como apunta Jean-Luc Nancy, cuando "un cuerpo parece cobrar sentido [...]. [cuando] La muerte paraliza el movimiento que suelta prenda y renuncia a moverse" (20).

En un segundo término se enfatiza la no identificación, el denominado cuerpo N.N. Sobreexpuesta a la implicidad de la muerte, la morgue se convierte en un lugar dantesco: los cadáveres cuelgan "de unos ganchos como reses" (Vallejo 172). La muerte iguala al hombre con el animal. Morgue matadero, morgue desolladero, "lugar del sacrificio, el espacio de las penas" (Franz 117).

Como expone Guadalupe Santa Cruz para los sitios sin marcas y las fosas sin nombres, "entre nombres y cuerpos se ha constituido y se constituye un trecho, una distancia, $[\ldots]$, que ha hecho también estallar lo posible: el horror de la realidad [...] por donde el hacer desaparecer un cuerpo, un nombre, una biografía, sería imaginable" (105). Nadie reclama el cuerpo N.N., doblemente invisibilizado: por la carencia de una identidad y por hallarse en pérdida respecto a la sociedad, ya que, la mayoría de las veces, corresponde a un delincuente, a un "basuquero alzado. [...] que se la pasan el día entero fumando basuco y pidiendo, exigiendo, con un garrote en la mano" (Vallejo 146147). El anonimato como elemento inherente: los cuerpos no identificados esconden su hoja de vida, no se exponen, y en esta anulación se condenan a un estado animal, de bestia destajada, trozos de carne atravesados por ganchos como si se guardaran en un frigorífico; luego "el Estado los entierra por su cuenta" (Vallejo 172), estocada final a un futuro posible reconocimiento, invisibilidad doblemente ejecutada. 
El autor cierra las páginas sobre la morgue con una imagen grotesca:

Lo último que vio fue un cadáver boca abajo en una mesa chorreando sangre de la cabeza sobre el piso, y en el mismo piso, en un rincón, una ropa tirada: unos pantalones, una camisa y unos zapatos. Un moscardón pasó zumbando, alborotando el olor fresquecito de la Muerte. (172).

Si literalmente se toma la descripción, surgen elementos contentivos del horror explícito que se contempla desde lo insoportable, sin metáforas: violencia, sangre, insectos, la muerte, su olor repulsivo... Una morgue donde los cuerpos se reducen a la condición abyecta, donde se les cancela su humanidad (o el resto de ésta). Cuerpos que "se cruzan, se rozan, se apretujan, se estrechan o se enfrentan: tantas señas se hacen, tantas señales, apelaciones, advertencias, que ningún sentido definido puede saturar" (19), alegaría Nancy. Aunque, mirándolos de cerca, sí existe un "sentido definido [que] puede saturar" en este lugar vallejiano: ser la última corporalidad donde confluyen la violencia social y la elección individual.

En La virgen de los sicarios, la morgue escenifica un remanente compartido entre los cadáveres que se entregarán a los deudos, para Vallejo "muertos vivos" (172); los cadáveres sin mortaja, los N.N., rastros de la nuda vida, en el término más apegado a Agamben (Lo que queda de Auschwitz. El archivo y el testigo y Homo Sacer); y quienes aguardan, éstos cuerpos en suspenso, cuerpos que lloran el desenlace de la violencia; todos implicados en la puesta en escena de un paradójico "Anfiteatro" con un único papel: ser los actores de la banalidad del horror.

\section{La morgue objeto. "La parte de los crímenes” (2666) de Roberto Bolaño}

Enfermo, conociendo el estado terminal de su padecimiento, Bolaño apuró la escritura de su última novela 2666, publicada en 2004, un año después de su muerte. Sólo le dio tiempo para revisar el primer capítulo ("La parte de los críticos") y algunas páginas del segundo ("La parte de Amalfitano") ${ }^{9}$. En "La parte de los crímenes", el cuarto capítulo, se nota cierto pulso apresurado, demasiados hechos que se cuentan en una secuencia agotadora. En un primer análisis (González 2010) observé que se trataba de un recurso para imitar la redacción de un informe policial; en este momento no estoy

\footnotetext{
${ }^{9}$ Durante el evento "Estrella distante. Congreso literario a diez años de la muerte de Roberto Bolaño", que se celebró en Chile del 15 al 18 de julio de 2013, conocí a Marta de la Vega, compañera sentimental del autor, quien me comentó que "La parte de los crímenes" fue el primer capítulo de la novela que escribió Bolaño. Lo refiero sólo como un dato curioso pues no he encontrado constancia de esto.
} 
segura, y redondeo esta idea con la imposibilidad del autor de depurar la narración; pero cualquier respuesta no influirá en el epicentro de la atención actual: la morgue que construyó en Santa Teresa ${ }^{10}$.

Morgue muy particular ciertamente, sobre todo cuando se constituye con las sobras de la violencia producida en serie por las maquilas que inundan la frontera entre México y los Estados Unidos, una problemática que difiere de la situación específica del narcotráfico en la sociedad colombiana. Alrededor de estas empresas, capaces de operar con mínimas cláusulas laborales a cambio de una remuneración más atractiva que en otras regiones, se ha instalado la violencia a través de la pugna entre bandas criminales y la impunidad del Estado frente a éstas. Ya ha transcurrido un largo tiempo desde que el imaginario de la violencia latinoamericana ha elaborado a Ciudad Juárez como un texto $^{11}$ complejo, fisurado, para acercarse a la ciudad globalizada, con su carga de crímenes y lacras, su contrato implícito entre la mano de obra barata y la barbarie neoliberal.

Una y otra vez Bolaño encadena cuerpos o fragmentos de éstos, listos para las manos del forense, como "una colección de piezas, de pedazos, de miembros, de zonas, de estados, de funciones. [...] colección de colecciones" (Nancy 23). Encadenamiento como una extensa enumeración de trozos, vestigios corporales, restos salvados de la voracidad de los animales en el Desierto de Sonora o en los basurales, porciones que se recogen en bolsas, en fin, una larga y exhaustiva fila que se sobresatura a medida que se desencadenan más crímenes en Santa Teresa.

Esta morgue se transforma en vertedero más que en el sitio depositario tradicional de cadáveres, en un erial de lo que se desecha. Los escasos cuerpos intactos o las piezas desmembradas se agrupan sin orden, van perdiéndose en una ruina casi idéntica a la del momento cuando se descubrieron. Doble degradación: las víctimas

\footnotetext{
${ }^{10}$ Ciudad a imagen de la compleja Ciudad Juárez, en el desierto mexicano de Chihuahua, donde, desde 1993 y hasta la fecha, según el Centro de Justicia para Mujeres de Ciudad Juárez, han sido asesinadas, torturadas y violadas más de 900 féminas. Para el escritor y periodista Sergio González Rodríguez, "Juárez encarnaría un territorio vehicular e intenso en todos los sentidos, un puente, un enclave de la economía multinacional, cuya industria maquiladora impone un paradigma que penetra y ordena el cuerpo de la sociedad" (40-41); mientras que para Mary Louise Pratt a través de Ciudad Juárez pueden observarse "las profundas transformaciones y aceleraciones de los patrones de movilidad humana, [siendo] dos de [las] formas más evidentes [de lo posmoderno] [...] la masiva migración de fuerza de trabajo y el turismo a gran escala. Este último constituye la industria más grande del mundo después del narcotráfico. La primera ha producido, entre otras cosas, una inversión del momentum difusionista de la modernidad, es decir, desde el centro hacia afuera" (“¿Por qué la Virgen de Zapopan fue a Los Ángeles? Algunas reflexiones sobre la movilidad y la globalidad" 4-5).

${ }^{11}$ La idea de leer la ciudad como un texto le corresponde a Susana Rotker en Ciudadanías del miedo (2000).
} 
violadas y abandonadas en descampados, chamizos o malezas, en el cinturón que acerca o bordea las maquiladoras, luego se condenan a la espera, al desahucio en una oficina improvisada como receptáculo de cadáveres y, la mayoría, al anonimato. Otra vuelta de tuerca a Vallejo en el sentido de la muerte sin nombre, en este caso de los cientos de mujeres que se multiplican sin identificación y sin individualidad.

Cual retahíla el capítulo entrecruza el hallazgo del cadáver (o sus jirones), su recolección, el traslado a una medicatura forense sin recursos, desvencijada, de pueblo orillado en el desierto de Sonora donde "Un enfermero [...], cogió el cadáver y lo metió en un congelador" (Bolaño 445) y la no resolución del crimen, que redunda en lanzar los cuerpos (o sus restos) en una fosa común. Esta morgue remite a un espacio de despojos, ritual de lo perecedero, de lo que no posee ni data de defunción y, mucho menos, dolientes:

El veinte de noviembre, [...], fue encontrado el cuerpo de una desconocida en un descampado de la colonia La Vistosa. Aparentemente la desconocida tenía unos diecinueve años y las causas de la muerte eran varias cuchilladas en el tórax, producidas por un arma con doble filo, todas o casi todas mortales. [...]. Cuando en el laboratorio del forense le quitaron el pantalón se encontraron con que debajo de éste llevaba otro pantalón, de color gris. [...]. Nadie reclamó el cuerpo. (Bolaño 618).

Partiendo de aquí pretendo situar en un primer plano la noción que la morgue bolañista es indistinta: puede ser móvil, estática o simplemente no existir. En la cita puede leerse fija, laboratorio del forense; en otros casos, el desierto se convierte en sitio para el examen: "a pocos kilómetros del ejido Gavilanes del Norte, se encontraron dentro de una bolsa de plástico los restos de una mujer. [...]. Según los forenses, la víctima tenía entre quince y diecisiete años de edad" (Bolaño 788); o el "tubo de desagüe que recorría bajo tierra la ciudad desde la colonia San Damián hasta la barranca El Ojito" (506). Quizá esto guarda relación con el interés del autor por lo dúctil y lo intercambiable, pues en su literatura poco se estratifica; parafraseando el conocido título del libro Todo lo sólido se desvanece en el aire de Marshall Berman, todo en Bolaño se desvanece no sólo en el aire sino en cualquier intersticio o cronología.

Así como se duplican y se dispersan los lugares del horror, también sucede con los sitios donde se diseccionan los cadáveres. La enumeración crea la metáfora de las cuentas de un collar: se ensarta una tras otra. Arenas del desierto, escombros, basureros, arbustos, matorrales... En cualquiera de estos sectores el forense va acampando, cuando 
puede hace "hincapié en el envío de las pruebas odontológicas" (Bolaño 686) o, lamentablemente, "sus conclusiones se perdieron tras ser archivadas" (641).

Bolaño aporta un segundo elemento desde donde hojear la morgue latinoamericana: ésta no sólo constituye el depósito de cuerpos (o de sus despojos), también se expone como un almacén de objetos inútiles y de los efectos personales de las víctimas, pero no de cualquiera sino del resto que sobrevivió a la violencia. Morgue clóset donde se amontonan prendas desteñidas, ajadas, que alguna vez fueron posesión de vidas y ahora permanecen sobre el piso, como los últimos rastros frente a la muerte. Prendas que se instituyen cual pequeñas manchas del horror. Prendas acumulativas de lo trunco, del pasado; prendas como calaveras que alegorizan la historia sufriente del mundo (Benjamin), en este caso, extendiendo la frase, la historia sufriente de Ciudad Juárez.

Un bluejeans, blusas, chamarras, un calzón con lacitos, unos zapatos de cuero... Semejante al extenso conglomerado de lugares convertidos en sitios de autopsias (muchos improvisados, como señalé) las piezas de las víctimas forman una morgue inanimada, siniestra. El autor iguala imágenes corporales, por ejemplo "La vagina estaba desgarrada. La vulva y las ingles presentaban señales claras de mordidas y desgarraduras" (Bolaño 577) con la de los objetos: "una manta [la cubría]" (578). Se produce una simbiosis: el cuerpo se trasvasa al de las pertenencias y ambos mueren, se desechan. Indistintamente una bolsa en el depósito forense puede guardar un brazo o un torso tajado como "unas mallas verdes, una playera blanca y unos tenis de color rosa" (575).

Este capítulo de 2666 se aglomera e impone una lógica del abandono. Como en la cinta de un proceso textil ${ }^{12}$, se colocan cuerpos tajados, objetos sin valor comercial, bolsas transparentes, mesas improvisadas de autopsias e informes incompletos. Amasijo sin distingo entre lo que potenció vida, las mujeres asesinadas en serie en Santa Teresa, y lo inanimado. Unas zapatillas deportivas se arrinconan y a su lado un saco hiede con los pedazos de una difunta. O el mismo cuchillo que produjo heridas "en los brazos y [...] en el tórax" (Bolaño 620) de una víctima de 14 años, también rasga una "blusa negra" (620).

\footnotetext{
${ }^{12}$ El cuerpo femenino, casi siempre anónimo, que atraviesa "La parte de los crímenes", resulta doblegado por un poder que lo silencia. Algunos teóricos e investigadores del tema como González Rodríguez, ya mencionado, vinculan los crímenes de Ciudad Juárez con el intento de acallar a la mujer con autonomía económica debido a su contratación como mano de obra en las maquiladoras, en una sociedad profundamente machista.
} 
La morgue uniforma el resto, se convierte en un armario de objetos que enuncia más al despojo que a las víctimas; que incrusta el resto como condición de identidad.

\section{Una morgue donde no se nombra el alma. "Autopsia" de Jacqueline Goldberg}

En 2006 la poeta venezolana Jacqueline Goldberg publicó "Autopsia” en su Poesía Reunida 2006/1986. Los poemas, breves, mantienen un ritmo coloquial, algunos inclusive pueden leerse como noticias de sucesos criminales metaforizadas por la muerte.

Un primer acercamiento me condujo a pensarlos de manera separada, sin embargo, la relectura posibilitó un vínculo que viene del título: el poemario se elabora como una enorme mesa de necropsia en donde confluyen cuerpos desconocidos, descompuestos, arrimados por la apatía de los vivos; y los poemas se sujetan a los cadáveres dejados, a la morgue que instala el desecho, el amontonamiento y la herida del abandono.

En la sala de Goldberg "los muertos dejan de existir [...] [proscritos] cada vez más lejos del grupo de los vivos" (Baudrillard El intercambio simbólico y la muerte 145) y la vida queda en el afuera, como contexto para algunos de los cuerpos: el de la hija jugando junto al cadáver de la madre; el de un padre que desentierra a su hijo de la fosa donde ambos fueron arrojados por unos delincuentes o el jardín de infantes al lado del depósito de residuos patológicos. La muerte se hace banal y a su alrededor la vida es un lastre, algo que se va soltando desde aquí.

La morgue del poemario tiene diferentes niveles de observación. Quizá el más explícito abarca la descripción del cuerpo como vaciadero de lo abyecto, de lo que se desintegra, el cuerpo mиerto como pecado, que molesta a los indiferentes:

Un cadáver es lo inmundo, lo inconfesable.

Maldición en la que concluye toda fiesta acusada de dolor. (69).

Y, más adelante:

El miedo impide

permanecer junto a la carne detenida,

respirar un cuerpo que es deserción.

Un cadáver es la conjetura apresurada del pecado. (71). 
Este cuerpo-cadáver ha dejado de ser "corpus corporum, cuya unidad sigue siendo una pregunta para ella misma" (Nancy 23) y debe apartarse ya que inspira miedo, insta a preguntarse por lo concluido; peca, no por cristiano sino por abandono de fe, por hallarse a la intemperie de la conmiseración social. No admite confesión y sella la gestualidad de verbalizar una palabra que redima como "política de vida" (Giddens). Cuerpo detenido que castiga con su inmovilidad. De ahí que "Suyo es por siempre el exilio, la brecha,/la imposible coartada" (Goldberg 71), elementos que pueden lastimar a los sobrevivientes atónitos.

La breve permanencia del cadáver se suscribe a un único lugar, la morgue, donde su exposición afianza "su pútrida y afanosa armadura" (Goldberg 70). Allí, con impudicia, el cuerpo vaciado por el forense se prepara para "volver a la sed,/verter su desierto" (71) en un sitio-ritual que lo acomoda para la sepultura, lo cual lo va alejando cada vez más del grupo de los vivos, expulsándolo de su circulación simbólica (Baudrillard El intercambio simbólico y la muerte) y por tanto no se absuelve de la condena de ser "aquel que miramos, mientras lo miramos" (70).

En este poemario se puede hilvanar un diálogo entre la exquisitez de los cadáveres de Noguchi, ya mencionados, como el de la actriz norteamericana Sharon Tate sobre cuyo crimen se concentró el patólogo y lo describió con detalles: "muerta por múltiples heridas de arma blanca. Yacía con las piernas replegadas sobre su estómago [...]. Estudié detenidamente el rostro [...] y advertí un roce en la parte inferior del pómulo" (132); y lo ordinario atravesado por una violencia que de tanto repetirse carece de importancia, sin médicos famosos que certifiquen la defunción y donde la morgue se instaura como un sitio de amontonamiento, pueblerino, con cuerpos que "rajan el aire con su leche somnolienta" (Goldberg 74), armonizándose este verso con la idea de Nancy acerca de los cadáveres que "se lleva[n] su secreto a la tumba. Solos, tal como los desahuciaron, apenas si nos quedan algunos indicios de su pasaje" (25).

Contraponiendo la artificiosidad del relato forense de Noguchi con la poesía de Goldberg, en ésta la muerte se relega a un parte médico sin rigurosidad: "Una insuficiencia respiratoria,/un zarpazo del amor desistido" (Goldberg 79); las identidades apenas se esbozan, "Miracle es el nombre de la niña/[...]/Lawarna Stevenson, la madre" (72); la escena criminal se imagina, a nadie le interesan los pormenores del asesinato: "El alguacil de la zona no precisó cuánto tiempo/estuvo el padre fruncido junto al muchacho,/cuánto silencio entró en sus pulmones" (73); y los lugares del horror nada tienen de glamorosos: una fosa improvisada, "un apartamento umbroso" (75) o una 
cocina con una despensa con algunos víveres que permitieron la alimentación de Miracle por unos días.

Frente a los cadáveres exquisitos están los del común, con historias también comunes pero fragilizadas en instantes por el horror del individualismo social: una niña juega junto al cuerpo en descomposición de su madre; un hombre a quien unos criminales entierran con su hijo y sobrevive a la agonía de su sepultura; la mujer que se abandona al lado del hermano muerto. Ellos resultan como sus relatos de existencia: sin sofisticados atributos. Como en sus vidas la muerte les preserva el anonimato y los expulsa aún más de entre los vivos.

El paroxismo de esta muerte insustancial, como un asunto al descuido, sin afán, se arma en el poema "EN BUENOS AIRES". Una guardería se entroniza con la morgue (y también con un depósito de residuos patológicos): la hora de llegada de los niños coincide con la del retiro de "las desembocaduras de la muerte" (Goldberg 74) y una furgoneta marca el trayecto entre la infancia inocente, la muerte y la putrefacción. El Jardín de Infantes $\mathrm{N}^{\circ} 4$ se transforma en un observatorio desde donde la mirada se petrifica ante los cadáveres que se trasladan continuamente: "'¿por qué están tapados?, ¿son muertos?'"' (74), pregunta un niño de cuatro años.

Como si cada cuerpo en tránsito detentara una potencia nefasta (Virilio y Baj), la morgue al lado de la guardería pone a contraluz la muerte, no la oculta ni la maquilla, al contrario la escupe frente al ojo infantil. Los niños visten una "perenne indumentaria de formol" (Goldberg 74) y contemplan el ir y venir de la furgoneta con su carga de residuos cancerosos y cadáveres descompuestos. No hay una cámara fotográfica que registre estos momentos anónimos, solitarios, deslastrados de su connotación de estupor de tanto reiterarse; como en los personajes de Vallejo, forman parte de una función que siempre terminó detrás del escenario.

Por último el poema "UN CUERPO SE DESCOMPONE" se sostiene desde la perspectiva del forense, como si estuviera abriendo el cuerpo mientras explica científicamente el proceso de su corrupción. Cada recuento de la devastación corporal alude a un estado progresivo del horror, el cual tiene que ver con el elemento donde se encuentre: la descomposición ocurre "casi dos veces más rápido en el aire/que cuando se halla hincado en el agua" (Goldberg 80). A partir de este verso/sentencia, se inicia un relato escatológico que ni siquiera la utilización de algunas metáforas libra de su significado hórrido, ya que todo se reduce a una "¡Pobre carne parda, reiterada de ayer,/supurando ínfimas conclusiones!" (81). 
Las neuronas y otras células como las de la piel y el útero fallecen; las uñas y el cabello semejan olvidos; las bacterias pululan en el adentro, como los moscardones y los gusanos alrededor del hedor a muerte; y "el páncreas cumple el augurio de devorarse a sí mismo" (Goldberg 80). Poco "aguarda [para] los triunfos del funeral" (80). Clínicamente el cuerpo adquiere la condición de cadáver. El presente lo vuelve rápidamente efímero, a semejanza del tiempo vívido por donde circuló. Nadie lo cuida, ni siquiera el forense con su faena escabrosa y técnica.

Pero en un momento de este extenso poema la descomposición se transforma en preludio de lo que acontecerá en el futuro con ese mismo cadáver, admitiendo más degradación:

Pasado un año, apenas quedan esqueleto y dentadura, con alguna traza de tejido aferrada.

$[\ldots]$

Los huesos demoran aún medio siglo en hacerse minucia.

La sospecha de la carne no es térrea, pero alude.

$[\ldots]$

Por eso no se nombra aquí el alma (Goldberg 81).

¿Qué permanecerá entonces no sólo después de la autopsia sino del enterramiento y del tiempo? Apenas restos, cenizas. Como apuntó Baudrillard en El intercambio simbólico y la muerte "Se han disuelto los conjuntos, se han desligado las energías, [...], para devolver las cosas a lo inorgánico” (174). La autopsia anula lo humano como materia y como símbolo y lo condena a una "tirana inmovilidad" (Goldberg 81). Cortado y vacío, yerto sobre la mesa de disección, "se gangrena" (82) cual "miasma extendida" (82).

La morgue de Goldberg expone el cuerpo que comienza a descomponerse, el horror y las historias comunes de sujetos echados a su suerte durante sus vidas. Quizá para la autora este cruce resulte el lugar que siendo "Tragedia [...] alivia los deberes de la eternidad" (82).

\section{Conclusión}

El proceso acelerado de la globalización invade hasta los espacios menos seductores del entramado social, en este caso el de la morgue, atravesada tradicionalmente por un discurso cuyos bordes se perfilan entre el tabú y la reticencia al 
nombramiento. Como bien apunta Baudrillard en La transparencia del mal. Ensayos sobre los fenómenos extremos, una de las formas de conjurar el acontecimiento aleatorio -y en este caso azaroso como el de la muerte- es precisamente condenándolo al silencio e instalándolo en un margen relegado.

De ahí pudiera desgajarse, ser la razón, el escaso trabajo de representación de la morgue en la literatura hispanoamericana contemporánea pues aunque la muerte constituye uno de los registros más elaborados tanto en la narrativa como en la poesía, uno de sus receptáculos, denominándolo así metafóricamente, no se ha potenciado de igual manera y si esto ha ocurrido, se visibiliza como el sitio maniqueo, por excelencia, del horror.

Haber resquebrajado esta perspectiva, conseguir una óptica otra, condujo al estudio de las narrativas de La virgen de los sicarios de Fernando Vallejo y "La parte de los crímenes" (2666) de Roberto Bolaño y de la poesía de Jacqueline Goldberg recogida en "Autopsia". En éstas ocurre un diferimiento hacia la literatura (en el término más apegado a Derrida) del desecho de la violencia y la indiferencia postmodernas, cada una con una propuesta particular: Vallejo y su morgue que autentifica el anonimato derivado de la práctica de la violencia en una sociedad neoliberal; Bolaño en la misma dirección de Vallejo pero añadiendo la cosificación absoluta del cuerpo vejado; y Goldberg quien entreteje en su poesía pequeñas historias de sujetos anulados en vida cuyo vano final se acrecienta sobre la soledad de la mesa de disección.

Cual calcinados tallos (verso de Goldberg) las morgues de estos autores producen -y he ahí la potencia del aporte- un imaginario más profundo que el de concebir una condición hórrida per se: ensamblan dentro de las sociedades neoliberales tanto la barbarie y las borraduras identitarias características del anonimato globalizado, que condenan al sujeto a la separación y el insilio; como aquellas muertes sin deudos, sin lágrimas y sobre todo "sin nombre" (Benn 10), muertes que habían sucedido antes en la soledad y el desprecio.

\section{Bibliografía}

Agamben, Giorgio. Lo que queda de Auschwitz. El archivo y el testigo. España: PreTextos, 2000. Impreso.

-------. Homo Sacer. Valencia, España: Pre-Textos, 2006. Impreso.

Ariès, Philippe. El hombre ante la muerte. Madrid: Taurus, 1999. Impreso.

Barthes, Roland. Mitologías. México: Siglo Veintiuno Editores, 1999. Impreso.

Bataille, Georges. Documentos. Caracas: Monte Ávila Editores, 1969. Impreso. La literatura y el mal. Madrid: Taurus, 1977. Impreso. 
Las lágrimas de Eros. Barcelona: Tusquets, 2000a. Impreso.

El erotismo. Barcelona: Tusquets, 2000b. Impreso.

--------. La oscuridad no miente. Madrid: Taurus, 2002. Impreso.

Baudrillard, Jean. El intercambio simbólico y la muerte. Caracas: Monte Ávila Editores, 1980. Impreso

----------. La transparencia del mal. Ensayos sobre los fenómenos extremos. Barcelona: Anagrama, 1997. Impreso.

--------. El crimen perfecto. Barcelona: Anagrama, 2000. Impreso.

Bauman, Zygmunt. Miedo líquido. La sociedad contemporánea y sus temores. Madrid: Espasa Libros, 2010. Impreso.

Benjamin, Walter. El origen del drama barroco alemán. Madrid: Taurus, 1990.Impreso.

Benn, Gottfried. Morgue. Caracas: Pequeña Venecia, 1991. Impreso.

Berman, Marshall. Todo lo sólido se desvanece en el aire. Madrid: Siglo XXI Editores, 2001. Impreso.

Bolaño, Roberto. "La parte de los crímenes". 2666. Barcelona: Anagrama, 2004, 441791. Impreso.

Derrida, Jacques. Cada vez única, el fin del mundo. Valencia: Pre-Textos, 2005.Impreso.

Escobar Henao, Juan Pablo. Pablo Escobar. Mi padre. Santiago de Chile: Planeta, 2014. Impreso.

Franz, Carlos. La muralla enterrada. Santiago de Chile: Planeta, 2001.

Giddens, Anthony. Modernidad e identidad del yo. El yo y la sociedad en la época contemporánea. Barcelona: Ediciones Península, 1995. Impreso.

Goldberg, Jacqueline. “Autopsia”. Verbos Predadores. Poesía reunida 2006/1986. Caracas: Editorial Equinoccio, 2007, 65-82. Impreso.

González, Daniuska. La escritura bárbara. La narrativa de Roberto Bolaño. Lima: Fondo Editorial Cultura Peruana, 2010. Impreso.

González Rodríguez, Sergio. Huesos en el desierto. Barcelona: Anagrama, 2002. Impreso.

Huxley, Aldous. Un mundo feliz. Madrid: Cátedra, 2013. Impreso.

Kristeva, Julia. Sol negro. Depresión y melancolía. Caracas: Monte Ávila Editores, 1997. Impreso.

Monsiváis, Carlos. "Ciudadanía y violencia urbana: pesadillas al aire libre”. Rotker, Susana (editora). Ciudadanías del miedo. Caracas: Nueva Sociedad, 2000, 231235. Impreso.

Nancy, Jean-Luc. Corpus. Madrid: Arena Libros, 2013. Impreso.

Noguchi, Thomas T. Cadáveres exquisitos. Barcelona: Global Rhythm Press y Ediciones Península, 2011. Impreso.

Ovejero, José. La ética de la crueldad. Barcelona: Anagrama, 2012. Impreso.

Pérez Morales, R.F. Las Fuentes del Miedo en H. P. Lovecraft (elementos fantásticos y de horror cósmico en "El sabueso" y "El color fuera del espacio"). Tesis Licenciatura en Literatura, Departamento de Filosofía y Letras, Escuela de Ciencias Sociales, Artes y Humanidades, Universidad de las Américas Puebla, México, 2007. Impreso.

Pratt, Mary Louise. “¿Por qué la Virgen de Zapopan fue a Los Ángeles? Algunas reflexiones sobre la movilidad y la globalidad". Contracorriente. 3.2 (2006): 133). Impreso.

Reguillo, Rossana. "La construcción social del miedo. Narrativas y prácticas urbanas". Rotker, Susana (ed.). Ciudadanías del miedo. Caracas: Nueva Sociedad, 2000, 185-201. Impreso. 
Salazar, Alonso. "Hacia una estrategia de la reconstrucción cultural”. En Rotker, Susana (editora). Ciudadanías del miedo. Caracas: Nueva Sociedad, 2000, 169181.Impreso.

---------. La parábola de Pablo. Auge y caída de un gran capo del narcotráfico. Bogotá: Planeta, 2012. Impreso.

Sánchez Rugeles, Eduardo. Jezabel. Caracas: Ediciones B, 2013. Impreso.

Santa Cruz, Guadalupe. "Capitales del olvido". En Richard, Nelly (edit.). Políticas y Estéticas de la Memoria. Santiago de Chile: Cuarto Propio, 2000, 105-112. Impreso.

Vallejo, Fernando. La virgen de los sicarios. Buenos Aires: Suma de Letras Argentina, 2005. Impreso.

Virilo, Paul y Baj, Enrico. Discurso sobre el horror en el arte. Madrid: Casimiro libros, 2010. Impreso. 